Journal of Social Science and Humanities, 4 (1): 06-11, 2021

e-ISSN: 2600 - 9056

(C) RMP Publications, 2021

DOI: $10.26666 / \mathrm{rmp} . j s s h .2021 .1 .2$

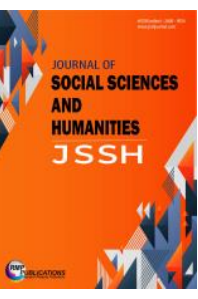

\title{
The Cultural Significance of Construction and International Communication Reflection of San Kong in Qufu, Confucius' Hometown
}

\author{
Yu Chunhua \\ Beijing International Studies University, Beijing, 10024 China
}

\begin{abstract}
In 1956, UNESCO confirmed the top ten cultural celebrities in the world, and Confucius was ranked first in the list. In recent years, "Confucius fever" has become a trend all over the world, and Confucius Institutes have been set up in many countries. Qufu, Confucius' hometown, is an important material carrier of Confucius thought, Confucian philosophy and Chinese culture. It is of far-reaching cultural significance. Its overseas communication has made some achievements, but still needs redoubled efforts. In the context of globalization, it is necessary to take measures to promote the global understanding of the San Kong, also called "The Three Confucian [sites]" in Qufu, including the Temple and Cemetery of Confucius and the Kong Family Mansion.
\end{abstract}

Keywords: Confucius, Temple and Cemetery of Confucius and the Kong Family Mansion, Cultural Significance, Overseas Communication

\section{INTRODUCTION}

At the beginning of the 20th century, Andersen's fairy tales were introduced into China, and they built beautiful fairy dreams for several generations of Chinese children. Denmark has become the "kingdom of fairy tales". Today, Andersen is regarded as the cultural symbol of the kingdom of Denmark. If only one person in China were to be chosen to represent Chinese culture in its long history, Confucius would be the best option. The Confucianism initiated by Confucius is the basic core of Chinese traditional culture. In recent years, "Confucius fever" has continued to heat up all over the world. In contrast, Qufu, the birthplace of Chinese Confucianism and the hometown of Confucius, has been neglected to a great extent by the rest of the world. In Denmark, Andersen's hometown, Odense on Funen Island, is a must for domestic and foreign tourists visiting Denmark. On the Chinese official website of the Danish Tourism Administration, the Andersen Cultural Festival is presented on the front page, and the Andersen museum is a must scenic spot on Funen island. However, the attractions in Qufu, especially San Kong, cannot receive such widespread coverage.

\section{World Cultural Heritage: San Kong in Qufu}

In the $20^{\text {th }}$ century, the world wars broke out and modernization advanced rapidly, which brought great damage to the natural landscapes and historical sites. UNESCO was aware that there was a growing tendency for the natural and cultural heritages to deteriorate. In 1972, UNESCO formulated the Convention Concerning the Protection of the World Cultural and Natural Heritage with a view to protecting irreplaceable cultural and natural properties in the world. The convention defines three categories of cultural heritages: cultural relics, buildings and archaeological sites. In 1994, San Kong in Qufu were included, which characterize material heritages, consisting of the ancient buildings and cultural relics of the Temple and Cemetery of Confucius and the Kong Family Mansion.I

The Temple of Confucius in Qufu was originally the residence of Confucius. In the Han Dynasty, Confucius' thought was highly respected in China. As the saying goes in China, "China's rites and music for thousands of years belong to Qufu, and the uncrowned king (refers to Confucius) is worshipped for thousands of generations." Liu Bang, the first emperor of the Han Dynasty, came to the Temple in Qufu to offer sacrifices to Confucius. During the reign of emperor Huan in the Eastern Han Dynasty, Han Chi, the Prime Minister of $\mathrm{Lu}$ (in the southwest of Shandong province now), presided over the renovation of the Temple, so that it became an official temple. During the period of Emperor

Corresponding Author: $\mathrm{Yu}$ Chunhua, Beijing International Studies University, Beijing, 10024 China. Email: yuchunhua513@163.com 
Taizong of the Tang, the central government ordered to the building of Confucius temples throughout the country, and the Confucius temple in Qufu was further repaired, upgraded and expanded. "Confucius temples as national examples" and "offering sacrifices to Confucius" have become Chinese social traditions. Sacrifice is a national event. The stone tablets among the Thirteen Stele Pavilion in the Temple of Confucius in Qufu record the experience of offering sacrifices to Confucius. The successive emperors granted Confucius posthumous titles, and continued to rebuild and expand the former houses, forming today's scale. Dacheng hall, the main building of the Temple in Qufu, is modeled after the imperial palace, and signifies that Confucius is the emperor in Chinese traditional culture. The eaves of Dacheng Hall are decorated with yellow glazed tiles, which could only be used for royal buildings at that time. The main building of the Temple is "built by red walls and with turrets at the four corners"[1], typifying the highest standard of Chinese traditional architecture. Accordingly, Confucius has a "holy" status in China. The Temple of Confucius in Qufu, the Forbidden City in Beijing and Chengde Mountain Resort (Imperial Summer Villa) are known as the most famous ancient architectural complexes in China. "The Temple of Confucius actually symbolizes the lofty position of Confucius and Confucianism in ancient Chinese society. It can be said that the history of worship in the Temple of Confucius is a history of official ideology, the evolution of orthodox ideological and cultural theories, and the epitome and symbol of Chinese traditional culture"'[2].

The Kong Family Mansion was the historical residence of the direct descendants of Confucius. Confucius was frustrated in his official career all his life, and his thoughts were not valued when he was alive. In the Han Dynasty, Emperor Gaozu of the Han went to the Confucius Temple in Qufu to offer sacrifices to Confucius, and granted Kong Teng, the 8th generation of the descendant of Confucius, the title of "Lord Fengsi" (also called "Ceremonial Officer"). Since then, despite the change of dynasties, the Kong family and the royal family have become the most respected families in Chinese history. In 1055, Zhao Zhen, the emperor Renzong of the Song, bestowed on Kong Zongyuan, the offspring of Confucius in the 46th generation, the title of "Duke Yansheng". A new mansion was awarded to Duke Yansheng, which was the original version of the Kong Family Mansion in existence now. Confucius carried out "Zhou Li" (the Rites of Zhou) all his life, in which the patriarchal system had a profound and everlasting influence in China up to modern times when China remained a typical patriarchal society; "the Kong family is the most typical historical specimen. From Confucius to his 77th generation, Kong Decheng, over 2,400 years, a special social and historical landscape has been formed with complete branches, clear family precepts and strict management system."[2] Duke Yansheng lived here to protect Confucius' relics and collect royal sacrificial vessels. Now the Kong Family Mansion covers an area of about 7.4 hectares, with 480 ancient buildings, nine courtyards in front and back, and three roads in the middle, east and west. From the perspective of architectural scale and layout, the present Kong Family Mansion is "a typical Chinese aristocratic mansion, which is regarded as 'the most honorable family in China"'[1].There are more than 100,000 pieces of historical relics in the collection, including not only bronze ritual vessels bestowed by the emperors of all dynasties, but also gold and stone, ceramics, jade, agate, pearls and calligraphy and paintings of celebrities of all dynasties. As a result, the Kong Family Mansion plays a role as a museum of Chinese cultural relics. The Kong family is a model for the inheritance of traditional Chinese families. The descendants of the Kong family can be supported by historical records. In 2005, the Kong family was listed as "the world's longest genealogy" in the Guinness Book of Records. The Kong Family Mansion is not only of great use in promoting Confucian culture, but also sets an example for the world to study the inheritance of the Chinese patriarchal clan system.

The Cemetery of Confucius is located 1.5 kilometers north of downtown Qufu, covering an area of more than 3.6 square kilometers. It is the family cemetery where Confucius, his disciples and his descendants were buried, with more than 100,000 tombs. "It has a history of more than 2500 years, and it is also the oldest and largest clan cemetery in the world. It is the largest, longest lasting and best preserved clan tomb group and artificial garden in China."[1] There is the Confucius Shinto in the Cemetery of Confucius, which is connected with the city gate. Confucius tomb is located in the middle of the Cemetery of Confucius, and is lined up with the tombs there, of his son Kong Li, and his grandson Zisi. "The momentum of horns, according to the guide, is "son and grandson as companion"'[3]. This is the layout of family tombs in ancient China. The Cemetery of Confucius is rich in cultural relics on the ground, which is of great value to the study of the Chinese burial system and ancient politics, economy, culture, customs, calligraphy and art. Today, there are still descendants of Confucius buried there. The family has lasted for generations.

The Temple and Cemetery of Confucius and the Kong Family Mansion are usually known as San Kong or "the Three Confucian Sites". "They are the symbol of commemorating Confucius and advocating Confucianism in Chinese history. They are famous for their rich cultural accumulation, long history, grand scale, rich cultural relics collection and high scientific 
and artistic value."[4] As the hometown of Confucius, Qufu is regarded as the "holy city of the East", and its cultural significance is worth investigating from many respects. As the material carrier of Confucian thought and the development of the Kong family, the Three Confucian Sites in Qufu worthy of in-depth understanding by scholars and tourists at home and abroad.

\section{The Cultural Significance of San Kong in Qufu}

"Qufu is the birthplace of Confucian culture, and the scenic spots in Qufu characterize the culture of Confucianism, the main ideology of the 'sage', with Confucius as the core figure, presenting more than 2,000 years of culture in China."'5] China is a vast country with five thousand years of history. As the only ancient country whose civilization didn't get interrupted among the four ancient civilizations, China takes the pride in its lasting civilization. Chinese scholars comment that "Confucius sorted out the great achievements of 2500 years before him and opened a new unification of 2500 years after him". Confucianism initiated by Confucius has been shining for thousands of years. Confucius advocated the practice of "Ren" (Benevolence) all his life. Mr. Fei Xiaotong, a famous sociologist in China, once said in his essay "Notes on Thinking in the Cemetery of Confucius", "this time I came to the Confucius Temple, I realized that the study of human beings in Chinese culture and has a long history. Confucius said "Ren" is the way to deal with the relationship between people and how to get along with each other. The Kong family has been passed to the 76th generation, which shows how long the continuity of Chinese culture is! Why do people want to protect it? Because it represents the most precious thing for the Chinese people, that is, how the Chinese people care about the coexistence of people."'[6] Professor Fei's writing expresses the historical and cultural significance of Qufu's San Kong in two dimensions. First, the existence of San Kong is "important evidence of the sustainable development of Chinese culture in a certain sense. Although historically several cities were invaded by foreign nations and destroyed from the inside, there have been few disputes about Qufu."[3] Second, San Kong, as the material carrier of Confucius thought, essentially show the unique features of China's ideological system: Fei emphasizes the spiritual core of " people's getting along with each other" in Confucius thought, and points out the fundamental difference between Confucianism and other beliefs, that is, "Confucianism has always 'enlightened people through heavenly principles', and its core is to care about people, the society people live in, but not much about the world after death. Therefore, Mr. Liang Shuming has said that Chinese culture was precocious and soon went out of belief and entered the period of rationalism.'[3] That's the reason why in China's history there are no church religions like those in western society.

Confucius, the representative of Chinese culture, still remains a mystery that needs to be explored. Today, we are in an era of "all things are media". San Kong in Qufu has become a media symbol to decode the inheritance and acceptance of Confucius' thought. The Confucius Temple maintains the legacy of sages, and the truth of world harmony; the Kong Family Mansion adheres to poetry and rites, and sets a good example for all generations; The Cemetery of Confucius keeps a good example of rites, and honors the late sages for their virtues. Taking the Confucius Temple as an example, Professor Li Jixiang once discussed the location of the Confucius Temple and the origin of its meaning at the world Confucian Congress where he also discussed the earthly significance of the Confucius Temple from two aspects. He points out that the Confucius Temple is a family temple of consanguinity because the descendants of Confucius sacrifice to their ancestors, but also represents "an ancestral temple world of nonconsanguinity because of Confucius as the master and ancestor and the domain of Confucianism"[7]. The descendants of Confucius are the first kind of worshipers, offering sacrifices to Confucius in the Confucius temples; also Confucius is an educator, so Confucius' disciples offer sacrifices to their ancestors, which form another special cultural etiquette. Confucius compiled "six books" and narrated the Analects of Confucius, ranging from governing the country, stabilizing the country and dealing with people. Confucianism is well-established and respected by later generations. In a broad sense, many people, including all Chinese people, are taught by Confucius, and they are all the students of Confucius. Offering sacrifices to Confucius and worshiping Confucius is not limited by the blood connection. As a cultural base, the Confucius Temple breaks through the limitation of blood relationship and national boundaries, and makes the most perfect annotation for the Confucian idea of "unity between man and nature".

The Cemetery of Confucius and the Kong Family Mansion are also realistic specimens for the investigation of the Confucian culture. Duke Yan 
Sheng, the descendant of the Kong family, abides by the precepts of their ancestors. Up to now, there is a red painted bench in the Kong Family Mansion, which is called "cold bench", also known as "Gelao bench". It is said that Yan Song, a powerful official of the Ming Dynasty, was impeached by the imperial court. In order to protect himself, Yan Song went to Qufu to ask his daughter's father-in-law, Kong Shangxian, who was Duke Yansheng at that time, to intercede with emperor Jiajing for him. Duke Yansheng was not moved. Yan Song sat on the bench outside the door for a day and had to leave bitterly. Accordingly, a cultural relic can be invested with a period of history. There are many such allusions in the Kong Family Mansion. Duke Yansheng has undoubtedly become an excellent practitioner of Confucius' thought, which provides a fresh case for studying Confucianism. So does the Cemetery of Confucius. The pines and cypresses towering overhead, the Cemetery of Confucius is not only a natural landscape, but also the overview of the family concept and the friendship between teachers and students in Confucianism.

\section{Reflection on International Communication of San Kong in Qufu}

In 1956, UNESCO identified the world's top ten cultural celebrities, with Confucius at the top of the list. San Kong in Qufu represent the long history of Chinese culture, and provides a realistic material carrier for world civilization. Therefore, Confucius has not only had a great influence in China, but also been beneficial to the world.

In recent years, China has taken relevant measures to make San Kong in Qufu known in the world :

First, the International Confucius Cultural Festival is held in Qufu every year. "The International Confucius Cultural Festival in China (Qufu) is a large-scale international festival to commemorate Confucius, the great thinker, educator and founder of the Confucian school. To some extent, the festival provides the rest of the world with exposure to the excellent traditional Chinese culture, international cooperation and global understanding in culture. So far, it has been successfully held 36 times, which has exerted extensive influence at home and abroad."[1] The International Confucius Cultural Festival is held in Qufu every year, which provides opportunities for foreign scholars and tourists to understand Confucian culture by visiting San Kong. In addition, the International Confucius Cultural Festival has been making efforts to become cosmopolitan. "In 1990, the Confucius Cultural Festival and UNESCO jointly set the activities, attracting more attention in the globe. In 2004, the Organizing Committee of the festival sent a delegation to South Korea, Japan, Hong Kong and other countries and regions to carry out cultural communication seminars, to increase know the ledge of festival. In 2005 and 2006, the Confucius Cultural Festival held activities both in the mainland of China, Taiwan, and the other areas to globally jointly sacrifice to Confucius. In 2010, the Confucius Culture Festival officially went abroad, when "the Confucius Week" was held with UNESCO in Paris. So far, the Confucius Cultural Festival has aroused more international attention."'[8] Thus, "the Three Confucian Sites" in Qufu have become an important window for the world to better understand Confucian culture.

Second, growing air and high-speed traffic is of great help to tourism in Qufu. In 2008, Qufu airport was built and was fully operational, which is convenient for foreign tourists for visiting Qufu directly by air. The Beijing-Shanghai high-speed railway was officially started in 2008. In 2011, the Beijing-Shanghai high-speed railway was put into operation and passed by Qufu east station. Since then, the journey from Beijing to Qufu only takes two hours by the high-speed railway, and that from Shanghai to Qufu only takes three hours. It turns out that the completion of Qufu airport and the Beijing-Shanghai high-speed railway have brought more tourists to San Kong in Qufu.

Third, a tour guide team has been improved to much like in 5A scenic spots. "In August 2011, Qufu was established as one of the three pilot cities of comprehensive reform of the national tour guide management system in Shandong province. Qufu has successively launched such measures like establishing a qualification certification system of 5A level scenic spot announcer for San Kong, setting up an annual independent guide trial pilot in Qufu, founding a joint-stock guide company, implementing the guide rating system, the whole process of supervising the fault exit system, etc.. These practices have proved effective and won good social response."[9] The establishment of a systematic guide training system for San Kong in Qufu benefits the tourist experience, provides tourists with an accurate explanation of history and culture, and promotes the global understanding of Confucianism. 
Although the international communication of San Kong in Qufu has had results, the popularity of San Kong in Qufu still can not match the worldwide "Confucius fever". Its overseas communication remains to be improved.

First, publicity of the International Confucius Cultural Festival needs to be generated. "The Confucius Cultural Festival is held every year in late September, which coincides with National Day Golden Week. When all tourist destinations are competing to attract tourists, the publicity of the Confucius Cultural Festival is relatively insufficient every year."[8] Browsing the relevant reports, we can find that the International Confucius Cultural Festival lacks early publicity, which makes the fact that it is more difficult to convey effectively to foreign tourists. As a result, the Confucius cultural festival only continuously affects people in Shandong or those in Qufu. Accordingly, the relevant departments can deeply explore the connotation of Confucius thought, integrate Confucius thought with contemporary topics, generate topics for the Confucius Culture Festival, and therefore attract Chinese and foreign scholars and tourists to Qufu for discussion with the practicality of solving problems.

Second, full use should be made of the local convenient transportation to achieve in-depth cooperation with the surrounding cultural cities. When foreign tourists visit China, their basic wish is to experience the Chinese culture, which is distinct from their native culture. Confucius, as a symbol of Chinese culture and a landmark figure of world civilization, is attractive for them. San Kong in Qufu can make the best of cultural aspects to build up cooperation with the Forbidden City in Beijing, Baotu Spring in Jinan, Mount Tai in Taian and other historical and cultural attractions, carrying out theme tourism activities such as "Chinese culture tracing", so as to take advantage of the popularity of other attractions to promote international communication of San Kong in Qufu.

Third, to actively advance cooperation with overseas Confucius Institutes. On the one hand, Confucius Institutes are a platform for foreign students to understand Chinese culture, where their study should not be limited to books and traditional classrooms. Visiting the Temple and Cemetery of Confucius and the Kong Family Mansion is a great opportunity and a vivid lesson for them to understand Chinese culture, so that they can experience the continuous development of Confucianism on the spot.
On the other hand, with the internationalization of San Kong in Qufu constantly strengthened, "the demand for foreign language talents and high-end tourism talents is very urgent. Furthermore, Qufu will improve the talent training and introduction mechanism to provide intellectual support for Qufu's tourism development."[9]

Fourth, making films and TV programs about Confucius and San Kong. Against the backdrop of high informationization, film and television has become an effective medium for mass communication. The overseas spread of palace drama has prompted a group of overseas tourists to visit the living places of emperor and concubines in the Forbidden City. Compared with the programs about the Forbidden City, the number of films and TV programs about Confucius or San Kong in Qufu are obviously insufficient. The international communication of San Kong in Qufu can be done along film and TV communication: on the one hand, we can"directly introduce San Kong through TV documentary programs", On the other hand, we can "directly or indirectly offer plot products"[10]. The combination of cultural heritage and TV media provides overseas audiences with a multi-sensory understanding of cultural heritage, which helps to attract more people to visit San Kong in Qufu and explore the footprints of sages.

\section{Conclusion}

In 1988, the winner of the Nobel Prize in physics, Hannes Alvin, once said, "if mankind is to survive it must go back 25 centuries in time to tap the wisdom of Confucius." San Kong in Qufu opens a direct and effective window to understand Confucius' thought, which is of great practical significance for mankind to create a new situation of inclusive and multicultural civilization in the 21 st century. The overseas communication effectiveness of San Kong in Qufu still has a long way to go. It needs to adapt to modernization, optimize communication and promote itself to be internationally.

\section{REFERENCES}

[1] The Central People's Government of the people's Republic of China, 2006. World Cultural Heritage: the Temple and Cemetery of Confucius and the Kong Family Mansion, http://www.gov.cn/test/200603/28/content_238291.htm, 2006-03-28 13:38. 
[2] Yang, C. M. 2004. Visiting the Temple and Cemetery of Confucius and the Kong Family Mansion: the holy land of Oriental culture, Shanghai: Shanghai Ancient Books Publishing House.

[3] Gan, C. S. 2014. Why Do We Go to Qufu? Yue Haifeng, (4), 89-91.

[4] 2015-03-16. World Cultural Heritage -- San Kong Scenic Spot in Qufu, China Tourism News.

[5] Sun J. H. 2014. The Combination of Three Confucius Scenic Spots in Qufu and Confucian Culture, Lantai World, (7), 140-141.

[6] Fei, X. T. 1992. Notes on Thinking in the Cemetery of Confucius, Reading, (9) , 3-7.
[7] Li, J. X. 2010. Space Location and Significance of "the Temple of Confucius" -- Cultural Space, Sacrificial Space, Political and Religious Space, Proceedings of the Third World Congress of Confucianism, 456-469.

[8] Feng, C. C. 2018. Based on the Festival Activities of Qufu City Image Communication Research -- Take Qufu International Confucius Culture Festival as an Example, Journal of News Research, 9(1), 51-52.

[9] Zhang, L. W. 2013-02-07. Building a Tour Guide Team Matching with 5A Scenic Spots, China Tourism News.

[10] Lyu, L. P. 2016. An Introduction to Film and Television Intercultural Communication, Beijing: China Radio Film and TV Press. 